\title{
Luna-Glob project in the context of the past and present lunar exploration in Russia
}

\author{
E M Galimov \\ V.I. Vernadsky Institute of Geochemistry and Analytical Chemistry, Russian Academy of Sciences, \\ Kosygin Str., 19, Moscow 119 991, Russia. \\ e-mail: galimov@geokhi.ru
}

The Russian Luna-Glob project has been conceived with a view to understand the origin of the Earth-Moon system. The objectives and main features of the Luna-Glob mission, which will mainly study the internal structure of the Moon by seismic instruments, are described in the context of the past and current program of lunar exploration in Russia.

\section{Introduction}

We have recently developed a model of the formation of Earth and Moon from a common cloud of particles of primitive (chondritic) composition (Galimov and Krivstov 2005a). The model predicts formation of two fragments, which become embryos of the Earth and Moon. Depletion of volatiles as well as of iron in the Moon is explained in this model to be due to the evaporation of particles. This model is an alternative to the 'Giant Impact Hypothesis', which suggests formation of the Moon from the Earth's mantle material ejected as a result of collision of Earth with a large (Mars size) body. Some geochemical characteristics of the Moon are difficult to reconcile with its origin from the Earth's mantle as proposed in the Giant Impact Hypothesis (Galimov 2004).

There are several geochemical criteria, which allow us to resolve between the various alternative models of the origin of the Moon. One of the key points is the concentration of the refractory elements including $\mathrm{Al}, \mathrm{Ca}, \mathrm{Ti}, \mathrm{U}, \mathrm{Th}$ and $\mathrm{Sr}$. At present there is no reliable estimate of the concentration of refractory elements in the bulk Moon. However, elastic properties of the mantle depend on its chemical and mineral composition, in particular, on $\mathrm{Al}_{2} \mathrm{O}_{3}$ content. The concentration of $\mathrm{Al}$ and hence other refractory elements can be esti- mated through seismic studies. One can show that if the Moon originated from the Earth's mantle, a very small core, not more than $0.4 \%$ of the lunar mass, is required. In contrast, if the Moon formed from the primary material it must have a core as massive as $5 \%$ of the total lunar mass. Thus the size of the lunar core is of crucial importance for resolving the problem of the Moon's origin. The current Russian Lunar Project 'Luna-Glob' has been conceived keeping the problem of the Moon-Earth origin in mind.

\section{Science goals of Luna-Glob mission}

The first objective of the Luna-Glob project is to conduct seismic experiments, which would allow us to get information on the internal structure of the Moon (figure 1). This is proposed to be carried out through two types of seismic experiments:

- small aperture seismic array with high-speed penetrators (HSP) and

- broadband seismometery (penetrator-landers, $\mathrm{PL})$.

The experiment based on the concept of small aperture seismic array has been proposed by $\mathrm{O}$ B Khavroshkin and other seismologists at the Institute of the Earth Physics in Moscow.

Keywords. Luna-Glob mission; lunar core; penetrators; seismology. 


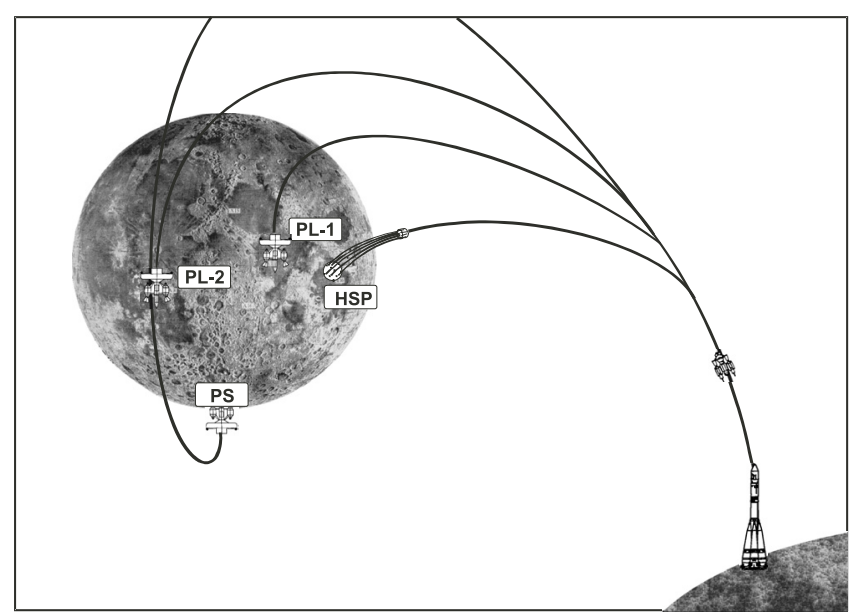

Figure 1. Lunar landing sites proposed in the Luna-Glob project. HSP - high-speed penetrators of the small aperture seismic array $\left(18^{\circ} \mathrm{S}, 38^{\circ} \mathrm{N}\right)$; PL-1 and PL-2 - penetratorlanders at $0.7^{\circ} \mathrm{N} 23.5^{\circ} \mathrm{E}$ and $3^{\circ} \mathrm{N}, 23.4^{\circ} \mathrm{W}$; PS - Polar Station $\left(88^{\circ} \mathrm{S}\right)$.

Preliminary calculations show that satisfactory results can be obtained by deployment of a network of 10 seismic sensors, which should be emplaced on the lunar surface by penetrators. The penetrators are expected to intrude into the lunar surface with high speed over an area of about $80 \mathrm{~km}^{2}(D=10 \mathrm{~km})$ within 2 to $3 \mathrm{~km}$ of each other.

The peculiarity of the small aperture seismic array experiment is that the penetrators are thrown from an approaching trajectory and intrude into the ground with high speed. In an extreme case (without any decelerating impulse) the speed of impact is expected to be $2.5 \mathrm{~km} / \mathrm{s}$. The shape of the penetrator is designed to reduce overloading and the scientific instrument is designed to survive a hard impact (up to 10,000 G). Preliminary tests show that the scientific instruments would survive under these conditions. The high-speed penetrators (HSP) are assembled into a ring cassette. The cassette is provided with a battery, solid-fuel engines and a control unit. The seismic array is best deployed in an area having low seismicity and thick regolith layer. A site in the Mare Fecunditatis $\left(18^{\circ} \mathrm{S}, 52^{\circ} \mathrm{E}\right)$ has been selected for emplacement of the seismic network.

The second seismic experiment is designed to use a broadband seismometer. Information about the interior of the Moon is limited due to the attenuation of seismic waves. The higher the frequency, the greater is the extent of attenuation. Therefore, it is essential to have an instrument with high sensitivity at low frequencies as in the broadband seismometer. Two landers carrying broadband seismometers will be deployed in the equatorial region of the Moon at a distance of about $300 \mathrm{~km}$ from

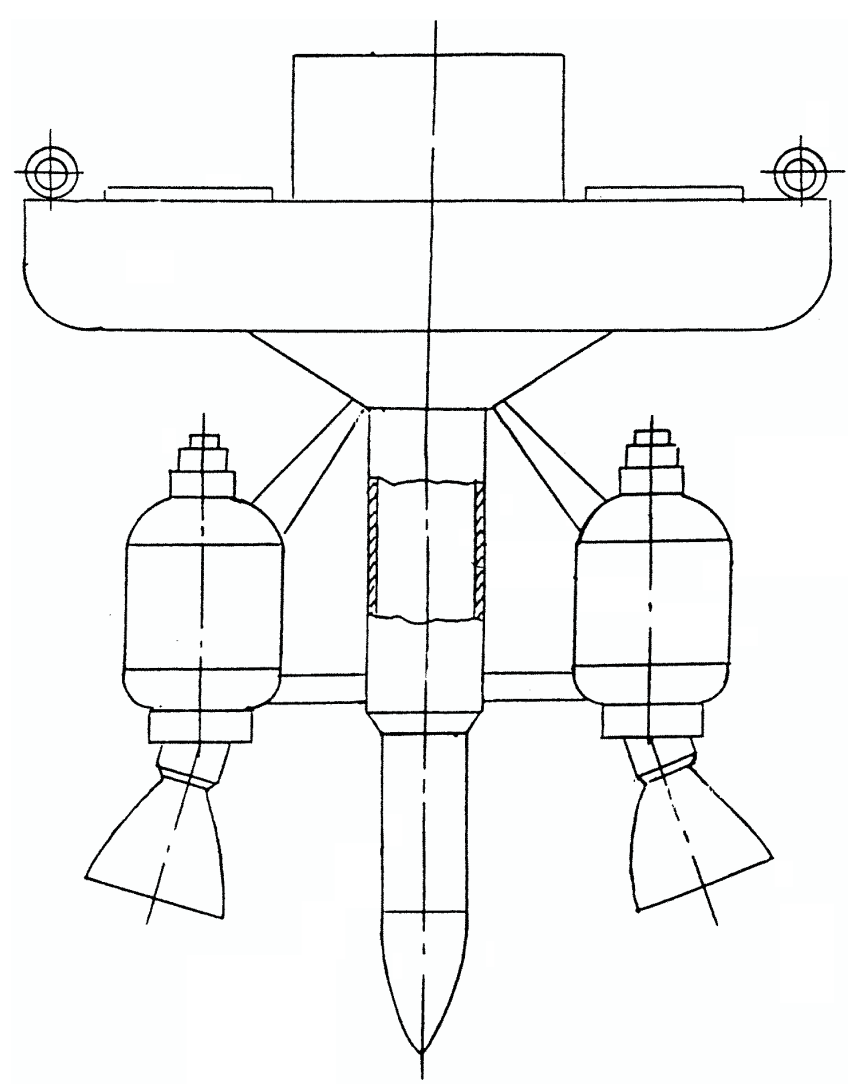

Figure 2. Design of the 'Luna-Glob' penetrator-lander.

each other. The landers will have the shape of a penetrator as shown in figure 2. Unlike the high-speed penetrator, the penetrator-lander will be equipped with decelerating engines, which will result in semi-hard landing $(80 \pm 20 \mathrm{~m} / \mathrm{s})$. The overload should not exceed $500 \mathrm{G}$. In addition, the penetrator contains radio transmitter, antenna, power supply, and a control unit. The sites with coordinates $0.7^{\circ} \mathrm{N}, 23.5^{\circ} \mathrm{E}$ and $3^{\circ} \mathrm{N}, 23.4^{\circ} \mathrm{W}$, near the landing places of Apollo 11 and Apollo 12, have been selected for the first and the second penetrators respectively.

The second objective of the Luna-Glob mission is to test the presence of volatiles including water in the polar regions of the Moon. In order to study the concentration of volatiles supposedly present in the permanently shadowed lunar polar regions, soft landing of the analytical station containing a mass-spectrometer and neutron spectrometer, combined with seismic station has been proposed. The polar station (PS) consists of a landing module, braking engine and inflated shock absorber. The braking engine first decelerates to leave the orbit and then decreases the vertical speed. Overload at the moment of shock on the lunar surface does not exceed $200 \mathrm{G}$. A crater of $56 \mathrm{~km}$ size with coordinates of the center $88^{\circ} \mathrm{S}, 38^{\circ} \mathrm{E}$ has been selected as its landing site. 


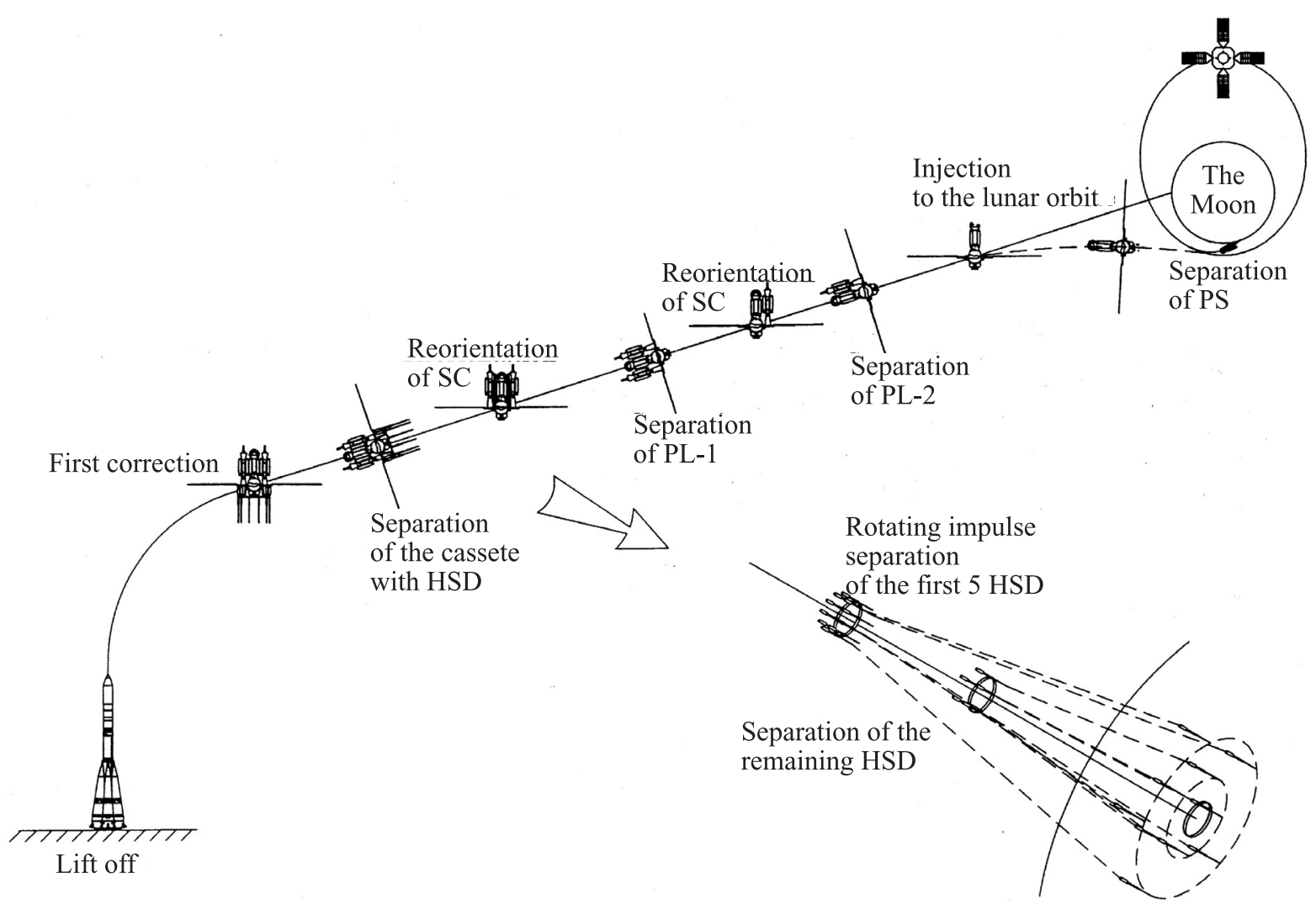

Figure 3. Schematic diagram of the mission profile of the 'Luna-Glob' project.

\section{Mission configuration}

Luna-Glob will be launched using either the 'Molnia' or 'Soyuz' rockets. The launch profile of the mission is shown in figure 3. Duration of the flight to the Moon is estimated to be 4.5 days. 29 hours before arriving at the Moon after correction and reorientation of the spacecraft, the HSP-carrying cassette is detached from the spacecraft. Then after reorientation, the first penetrator-lander, and after new reorientation, the second penetrator-lander are detached.

The HSP-cassette after detachment from the spacecraft moves along the hit trajectory rotating with $3 \mathrm{rad} / \mathrm{s}$. At $700 \mathrm{~km}$ altitude above the lunar surface, the rotation speed increases to $20 \mathrm{rad} / \mathrm{s}$ and the first set of HSP is detached from the cassette. The penetrators during their travel to the lunar surface, which will take about $250 \mathrm{~s}$, fly in a circle of diameter $\sim 8-10 \mathrm{~km}$. At an altitude of $350 \mathrm{~km}$, the remaining 5 penetrators leave the cassette and during the time of impacting on the lunar surface, fly in a circle of $5 \mathrm{~km}$ diameter.

The braking engines of PL are activated at an altitude of $2 \mathrm{~km}$, which decreases the speed to nearly zero. Then, the braking engines are detached and the penetrator enters the surface with a speed of about $60-120 \mathrm{~m} / \mathrm{s}$.

After releasing the HPL and PL, the spacecraft is injected into a polar circular orbit, selected to pass over the landing site of the polar station. The PS is detached from the spacecraft and decelerated to zero orbital speed. It descends to an altitude of about $2 \mathrm{~km}$, where the braking engines decrease the vertical speed to zero. The braking engines are ejected and the station touches the lunar surface with a speed of $5-25 \mathrm{~m} / \mathrm{s}$.

It is believed that the successful achievement of the objectives of the Luna-Glob project would result in a significant breakthrough in geosciences and planetology. Unfortunately there has not been much progress of this project since the Third Conference on Exploration and Utilization of the Moon held in Moscow in October 1998 (see Galimov et al 1999; Galimov 1998). The stagnation of the planetary research program in Russia is especially regrettable as we have unparalleled experience in the exploration of the Moon by automatic instruments, as summarized below. This experience could be helpful in collaborating with countries now planning their first lunar expeditions such as Japan, China and India. 
Table 1. History of lunar exploration* .

\begin{tabular}{|c|c|c|}
\hline Launch date & Mission & Accomplishment \\
\hline 2 Jan 1959 & Luna 1 & FIRST lunar flyby, magnetic field \\
\hline 12 Sept 1959 & Luna 2 & FIRST hard landing, magnetic field \\
\hline $20 \mathrm{Apr} 1960$ & Luna 3 & FIRST photos of lunar far-side \\
\hline 26 Jan 1962 & Ranger 3 & Missed the Moon by $36,793 \mathrm{~km}$ \\
\hline 23 Apr 1962 & Ranger 4 & Crashed on the lunar far-side \\
\hline 18 Oct 1962 & Ranger 5 & Missed the Moon by $724 \mathrm{~km}$ \\
\hline $2 \operatorname{Apr} 1963$ & Luna 4 & Missed the Moon by $8500 \mathrm{~km}$ \\
\hline 30 Jan 1964 & Ranger 6 & Hard landing, television failed \\
\hline 29 July 1964 & Ranger 7 & Hard landing, close-up TV \\
\hline 17 Feb 1965 & Ranger 8 & Hard landing, close-up TV \\
\hline 21 Mar 1965 & Ranger 9 & Hard landing, close-up TV \\
\hline 9 May 1965 & Luna 5 & Crashed on the Moon \\
\hline 8 June 1965 & Luna 6 & Missed the Moon by $161,000 \mathrm{~km}$ \\
\hline 18 July 1965 & Zond 3 & Photographed lunar far-side \\
\hline 4 Oct 1965 & Luna 7 & Crashed on the Moon \\
\hline $3 \mathrm{Dec} 1965$ & Luna 8 & Crashed on the Moon \\
\hline 31 Jan 1966 & Luna 9 & FIRST soft landing, $T V$ panorama \\
\hline 31 Mar 1966 & Luna 10 & $\begin{array}{l}\text { FIRST lunar satellite, gamma-spectra, magnetic } \\
\text { and gravity measurements }\end{array}$ \\
\hline 30 May 1966 & Surveyor 1 & On-surface TV, soil-mechanics \\
\hline 10 Aug 1966 & Lunar Orb 1 & TV imaging, radiation, micrometeorites \\
\hline 24 Aug 1966 & Luna 11 & Gravity, micrometeorites \\
\hline 22 Oct 1966 & Luna 12 & $T V$ imaging from orbit \\
\hline 6 Nov 1966 & Lunar Orb 2 & TV imaging, radiation, micrometeorites \\
\hline 21 Dec 1966 & Luna 13 & On-surface $T V$, soil mechanics \\
\hline 5 Feb 1967 & Lunar Orb 3 & TV imaging, radiation, micrometeorites \\
\hline 17 Apr 1967 & Surveyor 3 & On-surface TV, soil-mechanics \\
\hline 4 May 1967 & Lunar Orb 4 & TV imaging, radiation, micrometeorites \\
\hline 19 July 1967 & Explorer 35 & Fields and particles \\
\hline 1 Aug 1967 & Lunar Orb 5 & TV imaging, radiation, micrometeorites \\
\hline 8 Sept 1967 & Surveyor 5 & On-surface TV, first chemistry data \\
\hline 7 Nov 1967 & Surveyor 6 & On-surface TV, chemistry \\
\hline 7 Jan 1968 & Surveyor 7 & On-surface TV, chemistry \\
\hline 7 Apr 1968 & Luna 14 & Gamma spectra, magnetic measurements \\
\hline 14 Sep 1968 & Zond 5 & $\begin{array}{l}\text { FIRST lunar flyby and Earth return, returned bio- } \\
\quad \text { logical objects and photos }\end{array}$ \\
\hline 10 Nov 1968 & Zond 6 & $\begin{array}{l}\text { Lunar flyby and Earth return, returned biological } \\
\text { objects and photos }\end{array}$ \\
\hline 21 Dec 1968 & Apollo 8 & FIRST humans to orbit the Moon \\
\hline 18 May 1969 & Apollo 10 & FIRST docking in lunar orbit \\
\hline 13 July 1969 & Luna 15 & Failed robot sampler \\
\hline 16 July 1969 & Apollo 11 & FIRST humans on the Moon (20 July) \\
\hline 8 Aug 1969 & Zond 7 & $\begin{array}{l}\text { Lunar flyby and Earth return, returned biological } \\
\text { objects, photos }\end{array}$ \\
\hline 14 Nov 1969 & Apollo 12 & Human landing, Oceanus Procellarum \\
\hline 11 Apr 1970 & Apollo 13 & Aborted human landing \\
\hline 12 Sept 1970 & Luna 16 & FIRST robot sample return, Mare Fecunditatis \\
\hline 20 Oct 1970 & Zond 8 & $\begin{array}{l}\text { Lunar flyby and Earth return, returned photos, } \\
\text { landing in the Indian Ocean }\end{array}$ \\
\hline 10 Nov 1970 & Luna 17 & FIRST robotic rover Lunokhod 1, Mare Imbrium \\
\hline 31 Jan 1971 & Apollo 14 & Human landing, Fra Mauro \\
\hline 26 July 1971 & Apollo 15 & Human landing, Hadley-Apennine \\
\hline 2 Sept 1971 & Luna 18 & Failed robot sampler \\
\hline 28 Sept 1971 & Luna 19 & Orbiter, lunar gravity, TV, micrometeorites \\
\hline $14 \mathrm{Feb} 1972$ & Luna 20 & Robot sample return, Apollonius \\
\hline 16 Apr 1972 & Apollo 16 & Human landing, Descartes \\
\hline 7 Dec 1972 & Apollo 17 & $\begin{array}{l}\text { Human landing, FIRST geologist on the Moon, } \\
\text { Taurus-Littrow }\end{array}$ \\
\hline 8 Jan 1973 & Luna 21 & Lunokhod 2, Le Monier \\
\hline 29 Мay 1974 & Luna 22 & Orbiter, lunar gravity, TV, micrometeorites \\
\hline 28 Oct 1974 & Luna 23 & Failed robot sampler \\
\hline 9 Aug 1976 & Luna 24 & Robot sample return, Mare Crisium \\
\hline
\end{tabular}

${ }^{*}$ Soviet missions are shown in bold-italic, US missions are shown in normal font. 
Table 2. Spacecrafts launched in 2002 by various countries.

\begin{tabular}{lcc}
\hline \multicolumn{1}{c}{ Country } & $\begin{array}{c}\text { Number of } \\
\text { launches }\end{array}$ & $\begin{array}{c}\text { Number of } \\
\text { spacecrafts }\end{array}$ \\
\hline Russia & 25 & 35 \\
USA & 18 & 23 \\
Western Europe & 12 & 14 \\
China & 5 & 6 \\
Japan & 3 & 8 \\
India & 1 & 1 \\
Israel & 1 & 1 \\
\hline
\end{tabular}

Table 3. Scientific launches during 1996-2005 by various countries.

\begin{tabular}{lc}
\hline Country & $\begin{array}{c}\text { Number of } \\
\text { launches }\end{array}$ \\
\hline Russia & 1 \\
USA & 21 \\
ESA & 5 \\
Japan & 4 \\
\hline
\end{tabular}

\section{Historical perspective}

We now briefly describe the historical perspective of the Russian lunar exploration program for the study of the Moon in the context of space programs of various countries. The Russian missions carried out so far, for exploration of the Moon, are summarized in table 1 . The first spacecraft (Luna 1) was sent towards the Moon on January 2nd, 1959. In the same year Luna 2 hardlanded on the Moon. It was the first man-made object that landed on the lunar surface. The following year Luna 3 took the first photographs of the lunar far-side which humans had never seen before. In 1962-1965 America sent several spacecrafts of the Ranger series to the Moon. A significant achievement came when Luna 9 made the first soft landing and provided a TV-panorama of the lunar surface. In 1968, Zond 5 and Zond 6 were the first lunar flyby with biological objects and safely returned to Earth. In December 1968, the first humans orbited the Moon during the

Table 4. Spacecraft launches in Russia, 2002.

\begin{tabular}{|c|c|c|c|}
\hline Date & Carrier rocket & Spacecraft & Purpose \\
\hline 25 February & Soyuz-5 & Cosmos-2387 & Military \\
\hline 17 March & Rokot-Briz & Grace (USA) & On behalf of USA \\
\hline 19 March & Rokot-Briz & Colibri-200 & $\begin{array}{l}\text { On behalf of Australia } \\
\text { (partially of Russia) }\end{array}$ \\
\hline 21 March & Soyuz-5 & Program MI-8 & International Space Station \\
\hline 30 March & Proton-K & Intelsat-903 (USA) & $\begin{array}{l}\text { On behalf of USA (partially of } \\
\text { Russia) }\end{array}$ \\
\hline 1 April & Molniya-M & Cosmos-2388 & Military \\
\hline 25 April & Soyuz-5 & Soyuz-TM-34 & International Space Station \\
\hline 7 May & Proton-K & Direc TV-5 (USA) & On behalf of USA \\
\hline 28 May & Cosmos-3M & Cosmos-2389 & Military \\
\hline 10 June & Proton-K & Express-A No 4 & Communication \\
\hline 20 June & Rokot-Briz & Iridium-97, 98 (USA) & $\begin{array}{l}\text { On behalf of USA (partially of } \\
\text { Russia) }\end{array}$ \\
\hline 26 June & Soyuz-5 & Progress M-46 & International Space Station \\
\hline 8 July & Cosmos-3M & Cosmos-2390, 2391 & Military \\
\hline 25 July & Proton-K & Cosmos-2392 & Military (partially ecological) \\
\hline 22 August & Proton-K & EchoStar-8 (USA) & On behalf of USA \\
\hline 25 September & Soyuz-FG & Progress MI-9 & International Space Station \\
\hline 26 September & Cosmos-3M & Nadezhda & Navigational \\
\hline 15 October & Soyuz-5 & Foton-M No 1 & - \\
\hline 17 October & Proton-K & Integral (ESA) & $\begin{array}{l}\text { On behalf of ESA (partially of } \\
\text { Russia) }\end{array}$ \\
\hline 30 October & Soyuz-FG & Soyuz TMA-1 & International Space Station \\
\hline 25 November & Proton-K & $\begin{array}{l}\text { Astra-1 K } \\
\quad \text { (Luxembourg) }\end{array}$ & $\begin{array}{l}\text { On behalf of private compa- } \\
\text { nies SEC }\end{array}$ \\
\hline 28 November & Cosmos-3M & Mozhaets, Rubin-1 & $\begin{array}{l}\text { In behalf of Germany } \\
\text { (partially of Russia) }\end{array}$ \\
\hline 20 December & Dnepr-1 & $\begin{array}{l}\text { Rubin-2, LatinSat A, } \\
\text { SaudiSat-1C, } \\
\text { UniSat-2, Traiblazer }\end{array}$ & $\begin{array}{l}\text { On behalf of Germany, } \\
\text { Argentina, Saudi Arabia, } \\
\text { Italy and USA: } 5 \text { satellites }\end{array}$ \\
\hline 24 December & Molniya-M & Cosmos-2393 & Military \\
\hline 25 December & Proton-K & Cosmos-2394-2396 & Military \\
\hline 29 December & Proton-K & Nimiq-2 & On behalf of Canada \\
\hline
\end{tabular}


Apollo 8 mission, and on July 20th, 1969, Apollo 11 landed the first humans on the Moon's surface. After that there were the first automatic sample return missions (Luna 16, Luna 20 and Luna 24), first robotic rover Lunokhod-1 (1970) which were followed by five successful American human landings by Apollo missions. The last mission of that unprecedented lunar race was Luna 24, which automatically returned sample from Mare Crisium in August 1976.

As one can see from table 2, in 2002, for example, Russia had launched more spacecrafts than any other country. However, during the last decade, Russia has launched (unsuccessfully) only one spacecraft for the purpose of planetary research, while the United States has launched 21 (table 3). Table 4 gives an idea about the current program of Russian space launches, mainly with non-scientific objectives, such as for communication and military purposes. In this context, the Luna-Glob project will be a path-breaking mission in planetary and geoscience studies and will provide important data regarding the origin of the Moon.

\section{References}

Galimov E M and Krivstov A M 2005a Origin of the EarthMoon system; This Proceedings.

Galimov E M 1998 The Russian Lunar Project. Proc. ExploSpace Meeting, ESA, Sardinia, 20-22 Oct. 1998, pp. 1.1-1.6.

Galimov E M, Kulikov S D, Kremnev R S , Surkov Yu A and Khavroshkin O B 1999 The Russian Lunar Exploration Project; Solar System Research 33 327-337.

Galimov E M 2004 On the Origin of Lunar Material; Geochemistry International 42(7) 595-609. 